\title{
Índices fisiológicos do arroz irrigado afetados pela inundação e fertilização nitrogenada
}

\author{
Alberto Baêta dos Santos ${ }^{1 *}$, Luís Fernando Stone ${ }^{1}$, Alexandre Bryan Heinemann ${ }^{1}$,Talita Pereira Baêta Santos ${ }^{2}$
}

10.1590/0034-737X201764020003

\section{RESUMO}

Os manejos de água e de nitrogênio estão entre as intervenções necessárias para se atingir alto potencial produtivo nos sistemas agrícolas irrigados. Objetivou-se, com este estudo, determinar as influências de épocas de início da inundação e de aplicação do N em cobertura, nos estádios de desenvolvimento V3 - V4 a V12 - V13, nas características fisiológicas relacionadas positivamente com a produtividade de grãos do cultivar BRS Jaçanã, de arrozirrigado, em várzea tropical. Foi conduzido um experimento na Fazenda Palmital, da Embrapa Arroz e Feijão, em Goianira, GO, em um Gleissolo Háplico distrófico, por dois anos consecutivos. O delineamento experimental foi o inteiramente casualizado, com seis repetições, no esquema de parcelas divididas, constituídas pelas épocas da inundação e, as subparcelas, pelas épocas de aplicação de $90 \mathrm{~kg} \mathrm{ha}^{-1}$ de N em cobertura. Para os dois fatores, as épocas estabelecidas foram aos 15, 30, 45 e 60 dias após a emergência das plântulas, o que correspondeu aos estádios de desenvolvimento vegetativo V3 - V4; V6 - V7; V9 (VF4) - V10 (VF-3) e V12 (VF-1) - V13 (VF). Na medida em que o início da inundação se atrasa, aumenta o perfilhamento, a razão de área foliar (RAF) e a área foliar específica (AFE) e decresce a biomassa da parte aérea (BPA), o índice de área foliar (IAF) e a duração de área foliar (DAF). Épocas tardias de aplicação de N em cobertura também provocam decréscimos desses índices fisiológicos. O emprego da inundação e da adubação nitrogenada no arroz irrigado tardiamente reduz proporcionalmente mais a área foliar que a produtividade de grãos, o que resulta em maior eficiência de área foliar. A adubação nitrogenada em cobertura, efetuada por ocasião do início do perfilhamento, e a inundação contínua no período médio de perfilhamento resultam em aumento dos índices fisiológicos, como RAF, IAF e DAF, que estão relacionados positivamente com a produtividade de grãos do arroz irrigado.

Palavras-chave: Oryza sativa L.; crescimento; irrigação; manejo; nitrogênio em cobertura.

\section{ABSTRACT}

\section{Physiological indices of irrigated rice affected by flooding and nitrogen fertilization}

The management of water and nitrogen are among the necessary actions to achieve high yield potential in irrigated agricultural systems. The objective of this study was to determine the influence of time of the beginning of flood and $\mathrm{N}$ topdressing, in the development stages from V3 - V4 until V12 - V13, on physiological characteristics positively related to grain yield of irrigated rice cultivar BRS Jaçanã in a tropical wetland. A field experiment was conducted at Palmital farm of Embrapa Rice and Beans, Goianira, GO, Brazil, in a Dystrophic Haplic Gleysol, for two consecutive years. The experimental design was completely randomized with six replications arranged in a split-plot scheme. The main plots were comprised by the times of the beginning of flood and subplots by the times of $\mathrm{N}$ topdressing of $90 \mathrm{~kg}$ $\mathrm{ha}^{-1}$. For both factors, the times were set as 15, 30, 45, and 60 days after emergence, which corresponded to the vegetative development stages V3 - V4, V6 - V7, V9 (VF-4) - V10 (VF-3), and V12 (VF-1) - V13 (VF). As flood delays,

\footnotetext{
Submetido em 29/08/2014 e aprovado em 06/04/2016.

1 Embrapa Arroz e Feijão, Santo Antônio de Goiás, Goiás, Brasil. alberto.baeta@embrapa.br; luis.stone@embrapa.br; alexandre.heinemann@embrapa.br

2Instituto Federal de Goiás, Aparecida de Goiânia, Goiás, Brasil. talitapbs@ @otmail.com

*Autor para correspondência: alberto.baeta@embrapa.br
} 
tillering, leaf area ratio, and specific leaf area (SLA) increase and shoot biomass (SB), leaf area index, and leaf area duration decrease. Late $\mathrm{N}$ fertilization timing also provides decrease in these physiological indices. Delay in flooding and $\mathrm{N}$ fertilization reduced more leaf area than rice grain yield, resulting in higher leaf area efficiency. Nitrogen topdressing performed at the beginning of tillering and continuous flooding at the middle tillering stage result in increased physiological indices, such as leaf area ratio, leaf area index, and leaf area duration, which provide increase in irrigated rice grain yield.

Key words: Oryza sativa L.; growth; irrigation; management; nitrogen topdressing.

\section{INTRODUÇÃO}

Para maximizar a eficiência dos recursos naturais e de insumos, o manejo integrado da cultura de arroz irrigado é de fundamental importância, pois propicia aumento da produtividade da lavoura, reduz o custo de produção e minimiza os impactos ambientais negativos. Para isso, a irrigação permanente e a fertilização nitrogenada do arroz irrigado devem ser realizadas em épocas apropriadas. Água e nitrogênio (N) são dois fatores importantes no crescimento e desenvolvimento da planta de arroz e, frequentemente, suas deficiências causam decréscimo da produtividade de grãos. Fallah (2011) verificou interação de $\mathrm{N}$ e de métodos de irrigação sobre a biomassa do arroz, nos estádios de máximo perfilhamento e maturação fisiológica. A manutenção da lâmina de água na superfície do solo influencia os aspectos fisiológicos da planta de arroz, as condições físicas, químicas e biológicas do solo e interfere na disponibilidade de nutrientes.

$\mathrm{O} \mathrm{N}$ favorece o crescimento das plantas e aumenta os componentes da produtividade. É responsável pelo incremento da área foliar da planta, o que aumenta a eficiência de intercepção da radiação solar, a taxa fotossintética e, consequentemente, a produtividade de grãos. A carência de $\mathrm{N}$ é uma das que mais limitam a produtividade do arroz irrigado. A eficiência de recuperação de $\mathrm{N}$ pelo arroz inundado é menor que $50 \%$, em solos de várzea. A baixa eficiência de recuperação de $\mathrm{N}$ pelas plantas está associada com a volatilização, lixiviação, desnitrificação e erosão do solo (Fageria \& Baligar, 2005). A volatilização de amônia pode ser reduzida pelo manejo apropriado de $\mathrm{N}$, como o seu parcelamento, a época da primeira aplicação e o uso de fertilizantes nitrogenados menos propensos à volatilização. Scivittaro et al. (2010) determinaram que as perdas de N por volatilização de amônia variam com a umidade do solo e com o intervalo de tempo entre a primeira aplicação de $\mathrm{N}$ em cobertura e a entrada de água na lavoura. Parte do fertilizante nitrogenado aplicado ao solo é também imobilizada pelos micro-organismos e adsorvida aos coloides. Qi et al. (2012) relataram que a redução da dose de ureia na semeadura, o atraso da primeira aplicação de ureia ou a aplicação de sulfato de amônio aumentaram o crescimento das plantas de arroz, a produtividade de grãos, a absorção e a eficiência de recuperação de N. A acumulação de N nos grãos propicia efeito mais expressivo na produtividade do arroz, do que na absorção de N na palha (Fageria et al., 2009).

Para explicar as diferenças de comportamento das comunidades vegetais em estudos de nutrição, competição e relações solo-água-planta, vários índices fisiológicos são usados, tais como o índice de área foliar (IAF) e a duração da área foliar (DAF) (Pereira \& Machado, 1987). A análise de crescimento é fundamental para avaliação dos efeitos de sistemas de manejo sobre as plantas, pois descreve as mudanças na produtividade vegetal. É um método que segue a dinâmica da produção fotossintética e auxilia na compreensão dos processos morfofisiológicos da planta e sua influência sobre a produtividade. Fageria et al. (2008) atribuíram as diferenças da biomassa da parte aérea e da produtividade de grãos de arroz irrigado à capacidade fotossintética dos genótipos.

A hipótese, neste estudo, foi que existem épocas apropriadas de manejo da irrigação e da fertilização nitrogenada que propiciam melhoria dos índices fisiológicos que potencializam a produtividade de grãos de arroz irrigado. Com isso, objetivou-se determinar a influência de épocas de início da inundação e de aplicação do $\mathrm{N}$ em cobertura, nos estádios de desenvolvimento V3 - V4 ao V12 - V13, nas características fisiológicas relacionadas positivamente com a produtividade de grãos do cultivar BRS Jaçanã, de arrozirrigado, em várzea tropical.

\section{MATERIAL E MÉTODOS}

O estudo foi conduzido no Campo Experimental da Fazenda Palmital, da Embrapa Arroz e Feijão, no município de Goianira, GO, em um Gleissolo Háplico Ta distrófico de várzea, por dois anos consecutivos. As análises químicas, composição granulométrica e classe textural das amostras de solo coletadas no início do estudo, na camada de 0 a 0,10 $m$ de profundidade, revelaram 5,0 de $\mathrm{pH}$ em água (1:2,5); 4,2

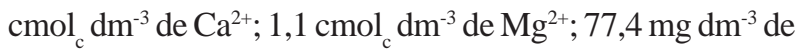
P; $55 \mathrm{mg} \mathrm{dm}^{-3} \mathrm{de} \mathrm{K}^{+} ; 3,5 \mathrm{mg} \mathrm{dm}^{-1} \mathrm{de} \mathrm{Cu} ; 4,2 \mathrm{mg} \mathrm{dm}^{-3} \mathrm{de} \mathrm{Zn}$; $385 \mathrm{mg} \mathrm{dm}^{-3} \mathrm{de} \mathrm{Fe} ; 31 \mathrm{mg} \mathrm{dm}^{-3} \mathrm{de} \mathrm{Mn} ; 27 \mathrm{~g} \mathrm{~kg}^{-1} \mathrm{de} \mathrm{MO}_{3} ; 23$ $\mathrm{g} \mathrm{kg}^{-1}$ de argila; $240 \mathrm{~g} \mathrm{~kg}^{-1}$ de silte; $437 \mathrm{~g} \mathrm{~kg}^{-1}$ de areia.Francoargiloso, respectivamente. 
Avaliaram-se os efeitos de quatro épocas de início da inundação, combinadas com quatro épocas de aplicação de N em cobertura, no cultivar BRS Jaçanã , de arroz irrigado. As épocas de aplicação dos dois fatores foram aos 15 , 30, 45 e 60 dias após a emergência (DAE) das plântulas, o que correspondeu aos estádios de desenvolvimento vegetativo V3 - V4 (formação do colar e, ou, lígula na $3^{\mathrm{a}}$ ou $4^{\mathrm{a}}$ folha do colmo principal - início do perfilhamento); V6 V7 (formação do colar e, ou, lígula na $6^{\mathrm{a}}$ ou $7^{\mathrm{a}}$ folha do colmo principal - metade do perfilhamento); V9 (VF-4) V10 (VF-3) (formação do colar e, ou, lígula na 9a ou 10a folha do colmo principal) e V12 (VF-1) - V13 (VF) (formação do colar e, ou, lígula na $12^{\mathrm{a}}$ ou $13^{\mathrm{a}}$ folha - folha bandeira do colmo principal), definidos de acordo com a escala de Counce et al. (2000). Em cada época, a adubação nitrogenada foi realizada em uma única aplicação, em cobertura, com $90 \mathrm{~kg} \mathrm{ha}^{-1} \mathrm{de} \mathrm{N}$, na forma de ureia. O delineamento experimental usado foi o inteiramente casualizado (Delineamentos Experimentais e Comerciais), conforme metodologia apresentada por Chacín Lugo (1997), com seis repetições, no esquema de parcelas divididas, constituídas pelas épocas de início da inundação, com $600 \mathrm{~m}^{2} \mathrm{e}$, as subparcelas, pelas épocas de aplicação de N, com $150 \mathrm{~m}^{2}$. Nos dois anos, foi empregado o sistema de semeadura em linhas, espaçadas de $0,17 \mathrm{~m}$, com 80 sementes por metro. Por ocasião da semeadura, aplicaram-se $400 \mathrm{~kg} \mathrm{ha}^{-1}$ do formulado 4 - 30 - 16, com base na análise do solo. A competição com as plantas daninhas foi prevenida com a aplicação do herbicida oxadiazon, na dose de $800 \mathrm{~g} \mathrm{ha}^{-1}$ de ingrediente ativo, em pré-emergência. Antes do início da inundação contínua, o solo foi mantido saturado por meio de inundações intermitentes. A supressão da irrigação ocorreu em uma única época para todos os tratamentos (R9 - maturação completa dos grãos). Durante o período de irrigação foi mantida uma lâmina de água uniforme de cerca de $10 \mathrm{~cm}$.

Para as análises de crescimento, foram realizadas amostragens da parte aérea dos perfilhos, em uma linha de plantio de $0,50 \mathrm{~m}$, em cada unidade experimental, $150 \mathrm{~m}^{2}$, em seis repetições, iniciando-se aos 15 DAE e, as subsequentes, em intervalos de 14 dias até a colheita. Foi contado o número total de perfilhos e foram separadas as folhas e bainhas mais colmos de 20 perfilhos, ao acaso, e o restante da amostra. As subamostras foram acondicionadas em sacos de papel devidamente identificados, levadas para secagem a $65^{\circ} \mathrm{C}$, até atingir massa constante, e pesadas para obtenção das biomassas de folhas $\left(\mathrm{BF}_{20 \text { per }}\right)$ e de colmos $\left(\mathrm{BC}_{20 \text { per }}\right)$, que foram ajustadas para $1 \mathrm{~m}^{2}$. A área foliar de 20 perfilhos $\left(\mathrm{AF}_{20 \text { per }}\right)$ foi determinada com medidor automático modelo LI 3000.

As curvas de crescimento da BPA e do IAF foram ajustadas, em função do tempo por equações de regressão, testando-se modelos exponenciais quadráticos. A razão de área foliar (RAF) foi obtida pelo quociente entre a AF e a BPA, em dm² $\mathrm{g}^{-1}$; a duração da área foliar (DAF), pela integração da curva do IAF em função do tempo, em $\mathrm{m}^{2}$ dia $\mathrm{m}^{-2}$; a área foliar específica (AFE), pela relação entre a AFe a BF, em $\mathrm{dm}^{2} \mathrm{~g}^{-1}$; a razão de massa foliar (RMF), pela relação entre a BF e a BPA, em $\mathrm{g} \mathrm{g}^{-1}$; e, a eficiência de área foliar (EAF), pela relação entre a produtividade de grãos e a DAF. A produtividade de grãos foi expressa em $\mathrm{kg} \mathrm{ha}^{-1}$, após a umidade ser ajustada para 13\%. Os dados dos índices fisiológicos obtidos no florescimento foram submetidos à análise de variância e, quando significativos, à análise de regressão.

\section{RESULTADOS E DISCUSSÃO}

Os efeitos das épocas de início da inundação e de aplicação do N sobre a BPA e o IAF das plantas de arroz estão expressos nas Figuras 1 e 2. Os melhores ajustes da BPAe do IAF, em função do tempo, foram obtidos por equações exponenciais. A evolução da BPA, em relação às mudanças ontogenéticas, mostrou que as diferenças entre as épocas de início da inundação e de aplicação do $\mathrm{N}$ aumentaram com o desenvolvimento das plantas de arroz, intensificando-se durante a fase reprodutiva da cultura até o período de enchimento de espiguetas, quando ocorreram os valores máximos (Figura 1).

No primeiro ano, as máximas biomassas da parte aérea foram obtidas com a inundação iniciada aos $15 \mathrm{DAE}$, e estimada, por meio da equação de regressão, em $1.307 \mathrm{~g} \mathrm{~m}^{-2}$, aos 89 DAE, e a adubação nitrogenada, efetuada aos 30 DAE, e estimada em $1.238 \mathrm{~g} \mathrm{~m}^{-2}$, aos 85 DAE. No segundo ano, isso se verificou com a inundação iniciada aos 45 DAE, e estimada em $1.323 \mathrm{~g} \mathrm{~m}^{-2}$, aos $101 \mathrm{DAE}$, e o N, aplicado aos 15 DAE, e estimada em $1.311 \mathrm{~g} \mathrm{~m}^{-2}$, aos $88 \mathrm{DAE}$ (Figura 1). Ao comparar fontes de N, Fageria et al. (2011) verificaram que a maior produtividade de grãos foi associada com maiores biomassas da parte aérea e com os componentes da produtividade do arroz. Fageria et al. (2008) obtiveram relação quadrática entre a BPA e a produtividade de grãos. Portanto, melhoria da BPA é uma medida para aumentar a produtividade de grãos de arroz irrigado. Os autores mencionaram que o manejo adequado de $\mathrm{N}$ é uma estratégia para melhorar a BPA e, consequentemente, a produtividade de grãos. Falqueto $e t$ al. (2009) relataram que os cultivares de arroz irrigado diferem quanto ao padrão de distribuição de matéria seca em cada órgão durante o período de enchimento de grãos.

As diferenças entre os efeitos dos manejos de água e de $\mathrm{N}$ sobre o IAF também aumentaram com o desenvolvimento das plantas, intensificando-se ainda mais durante a fase reprodutiva até o pleno florescimento, quando ocorreram os máximos IAF (Figura 2). Em geral, à medida que foram retardadas a inundação e a aplicação de $\mathrm{N}$ em cobertura, menores foram a BPA e o IAF. O emprego da inundação e da adubação nitrogenada no estádio de desenvolvimento 
vegetativo V3 - V4, ou seja, formação do colar na $3^{\mathrm{a}}$ ou $4^{\mathrm{a}}$ folha do colmo principal, propiciou maior biomassa, o maior valor de IAF, com alta capacidade de aproveitamento da área disponível. O efeito do manejo de $\mathrm{N}$ refletiu-se na produtividade de grãos do cultivar BRS Jaçanã, que declinou linearmente com o atraso da aplicação de $\mathrm{N}$ nos dois anos (Figura 3), ao passo que, isoladamente, as épocas de início da inundação não tiveram efeito significativo na produtividade de grãos, pois não apresentaram comportamento definido. Bosco et al. (2009) relataram que o arroz cultivado em solo não alagado apresentou redução do crescimento e desenvolvimento vegetativo, com menores crescimento e velocidade de emissão das folhas e duração mais longa da fase de início do perfilhamento até a diferenciação da panícula.

O incremento do IAF até a floração deu-se pelo aumento do número de folhas e pela expansão do limbo foliar. Após o florescimento, houve decréscimo do IAF, o que era esperado, pois a senescência das folhas reduz a área foliar verde. As plantas de arroz apresentaram três fases de crescimento: na fase inicial, o crescimento foi lento, da emergência das plântulas ao início do perfilhamento; com isso o IAF e o acúmulo de biomassa da parte aérea foram pequenos. Poste-

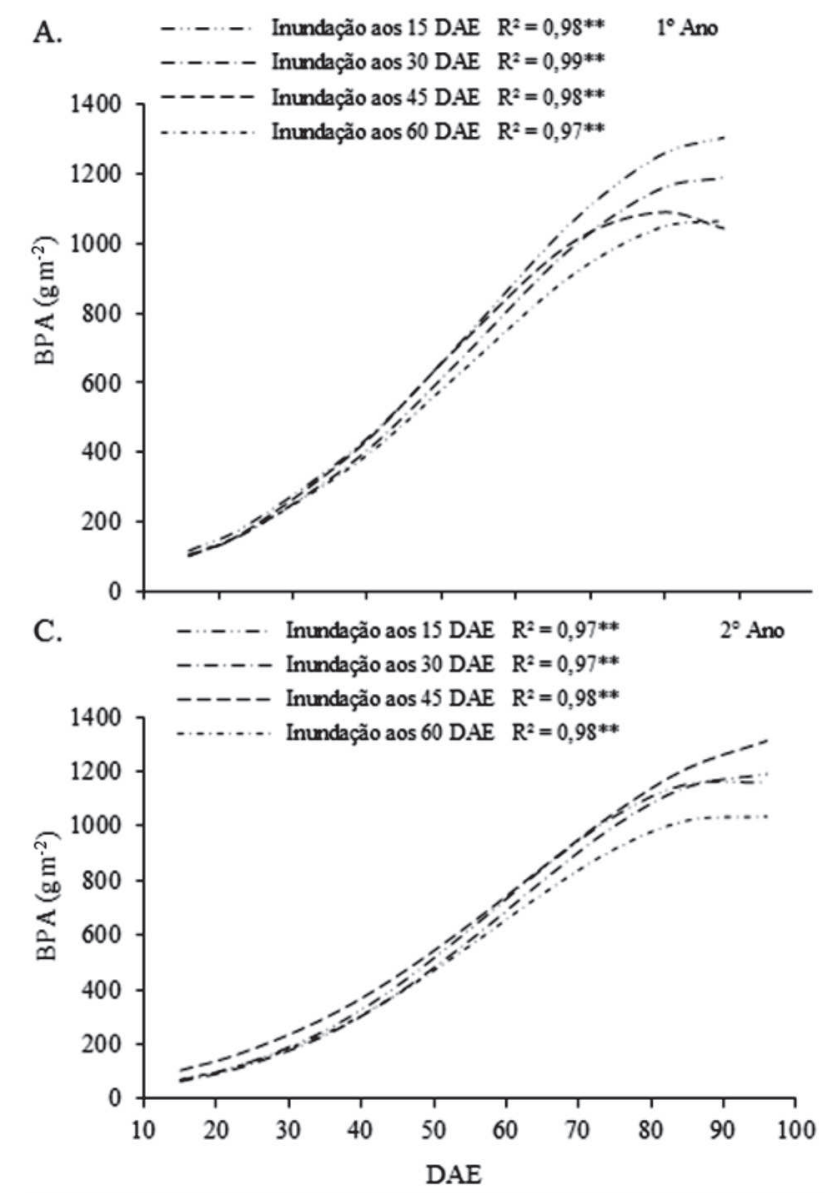

riormente, o crescimento foi acelerado até o florescimento, quando então o IAF começou a diminuir e, o crescimento, a tornar-se estável, em decorrência da senescência, que se reflete, inicialmente, na paralisação da produção de matéria orgânica. Nesse estádio, começam a prevalecer os fenômenos de translocação, em substituição aos de crescimento. Carlesso et al. (1998) relataram que o início da irrigação aos 15 DAE proporciona maior dossel vegetativo e altura de plantas, com consequente maior área foliar fotossinteticamente ativa na fase inicial de desenvolvimento. Nessa fase da cultura do arroz, com o atraso da época de início da irrigação de 15 para 30 DAE, sem a aplicação de herbicidas, os autores verificaram redução do IAF. Marchesan et al. (2013), avaliando a resposta do arroz irrigado ao uso de ureia recoberta com inibidor de urease, verificaram que o estresse causado na planta pelo atraso do início da inundação é mais prejudicial do que as perdas causadas pela volatilização de $\mathrm{NH}_{3}$.

Por ocasião do florescimento, o número de perfilhos por área, no primeiro ano, apresentou resposta quadrática às épocas de aplicação de $\mathrm{N}$ em cobertura, sendo $35 \mathrm{DAE}$ a época estimada, por meio da equação de regressão, para a obtenção do perfilhamento máximo. No segundo ano,

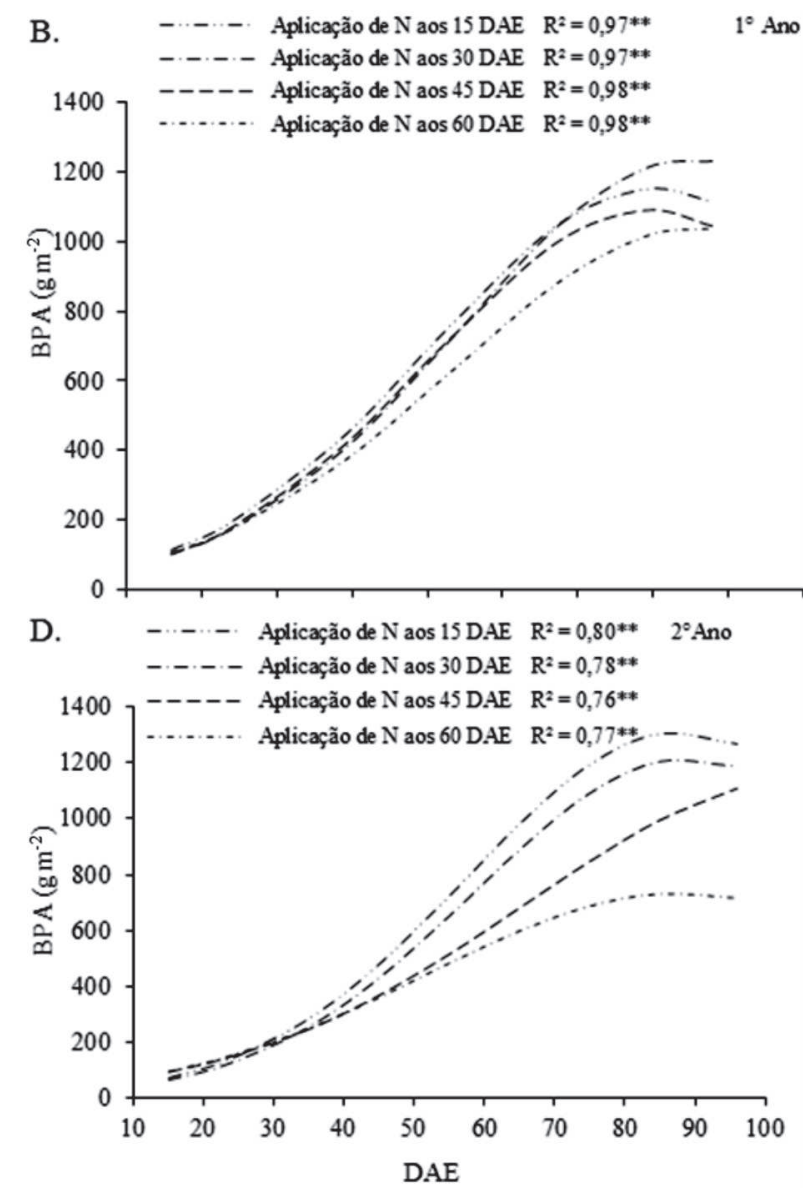

Figura 1: Evolução da biomassa da parte aérea (BPA) do cultivar BRS Jaçanã de arroz irrigado, em relação às épocas de início da inundação (A.) (C.) e de aplicação do N (B.) (D.) nos dois anos. 
A.
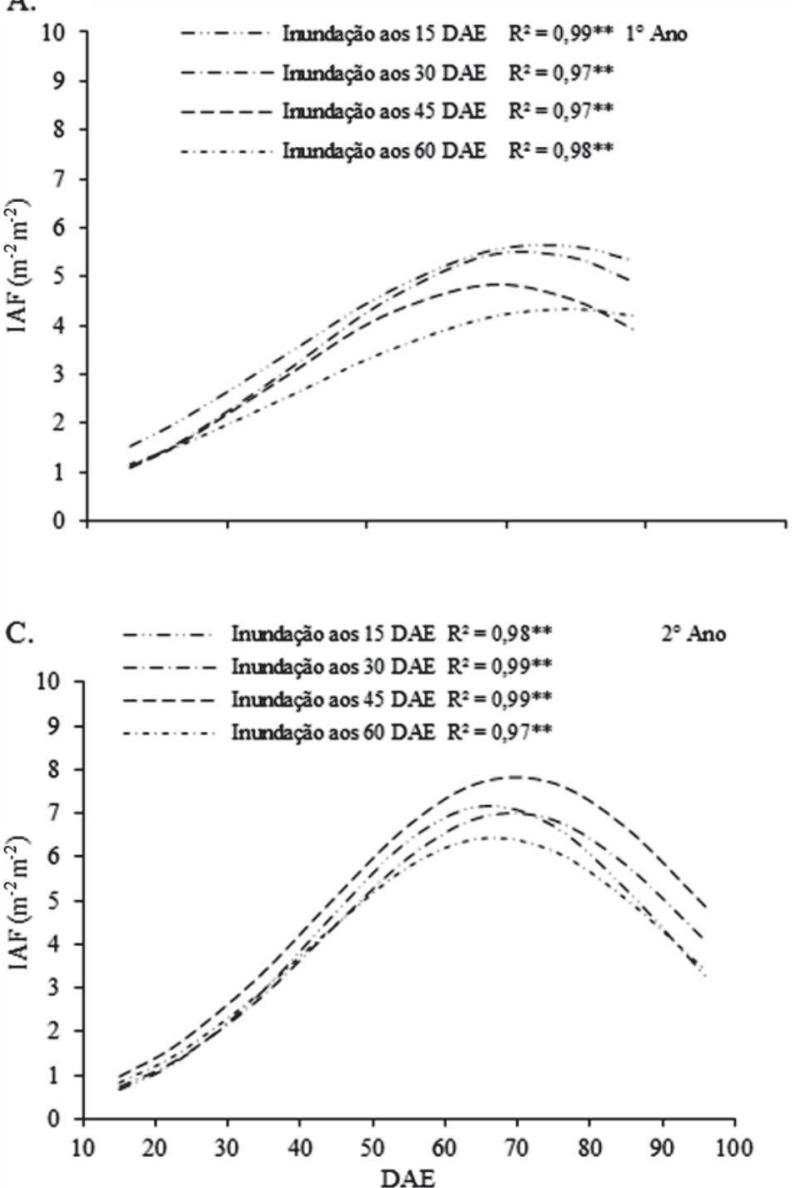
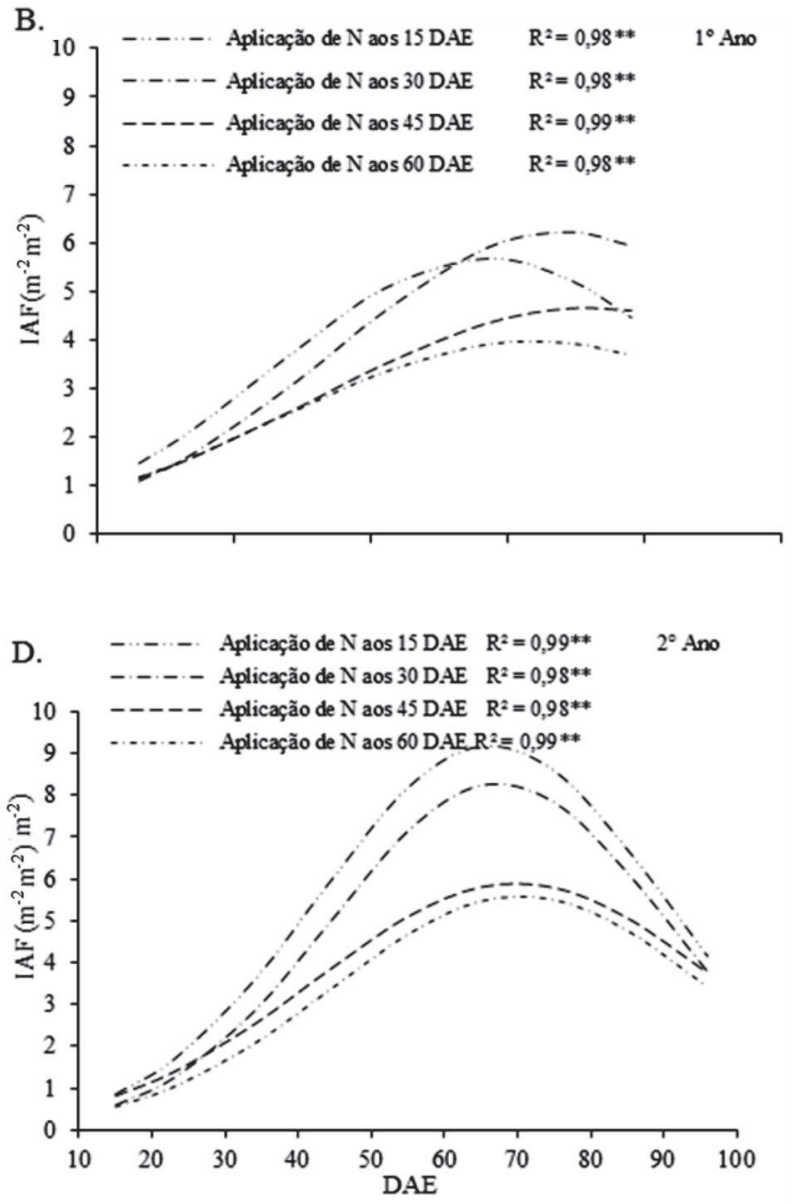

Figura 2: Evolução do índice de área foliar (IAF) do cultivar BRS Jaçanã de arroz irrigado, em relação às épocas de início da inundação (A.) (C.) e de aplicação do N (B.) (D.) nos dois anos.

Tabela 1: Equações de regressão de índices fisiológicos no florescimento do cultivar BRS Jaçanã de arroz irrigado, em resposta às épocas de início da inundação e de aplicação do N, nos dois anos, e coeficientes de determinação $\left(\mathrm{R}^{2}\right)$

\begin{tabular}{|c|c|c|c|c|}
\hline Característica $^{1}$ & Ano & Tratamento & Equação de regressão & $\mathbf{R}^{2}$ \\
\hline \multirow{2}{*}{ Perfilhos $\left(\mathrm{n}^{\mathrm{o}} \mathrm{m}^{-2}\right)$} & $1^{\circ}$ & Manejo de N & $y=462+18,0350 x-0,2558 x^{2}$ & $0,73 * *$ \\
\hline & $2^{\circ}$ & Manejo de água & $Y=618+2,5736 x$ & $0,35^{* *}$ \\
\hline \multirow{3}{*}{ BP de um perfilho $(\mathrm{g})$} & $1^{\circ}$ & Manejo de água & $y=2,16-0,0119 x$ & $0,79 * *$ \\
\hline & \multirow{2}{*}{$2^{\circ}$} & Manejo de água & $\mathrm{y}=1,13+0,0343 \mathrm{x}-0,00054 \mathrm{x}^{2}$ & $0,99 * *$ \\
\hline & & Manejo de $\mathrm{N}$ & $y=1,85-0,0092 x^{2}$ & $0,68 * *$ \\
\hline \multirow{2}{*}{$\mathrm{BF}\left(\mathrm{g} \mathrm{m}^{-2}\right)$} & \multirow{2}{*}{$2^{\circ}$} & Manejo de água & $y=34,48+7,8848 x-0,1126 x^{2}$ & $0,83 * *$ \\
\hline & & Manejo de N & $Y=200,51-1,6075 x^{2}$ & $0,74 * *$ \\
\hline $\mathrm{BC}\left(\mathrm{g} \mathrm{m}^{-2}\right)$ & $2^{\circ}$ & Manejo de N & $y=1108-5,1856 x$ & $0,70 * *$ \\
\hline $\mathrm{BPA}\left(\mathrm{g} \mathrm{m}^{-2}\right)$ & $2^{\circ}$ & Manejo de N & $y=1309-6,7931 x$ & $0,71 * *$ \\
\hline \multirow{3}{*}{$\operatorname{IAF}\left(\mathrm{m}^{2} \mathrm{~m}^{-2}\right)$} & \multirow{2}{*}{$1^{\circ}$} & Manejo de água & $y=6,67-0,0303 x$ & $0,77 * *$ \\
\hline & & Manejo de N & $y=3,36+0,1952 x-0,0031 x^{2}$ & $0,75^{* *}$ \\
\hline & $2^{\circ}$ & Manejo de N & $Y=7,53-0,0558 x$ & $0,82 * *$ \\
\hline $\operatorname{RAF}\left(\mathrm{dm}^{2} \mathrm{~g}^{-1}\right)$ & $1^{\circ}$ & Manejo de $\mathrm{N}$ & $y=0,37+0,0097 x-0,0002 x^{2}$ & $0,54 * *$ \\
\hline \multirow{2}{*}{$\operatorname{RMF}\left(\mathrm{g} \mathrm{g}^{-1}\right)$} & $1^{\circ}$ & Manejo de N & $\mathrm{y}=0,28-0,0012 \mathrm{x}$ & $0,33^{*}$ \\
\hline & $2^{\circ}$ & Manejo de água & $y=0,054+0,0059 x-0,00009 x^{2}$ & $0,98 * *$ \\
\hline
\end{tabular}

$*$ e $* *$ Significativo a 5 e $1 \%$ de probabilidade, respectivamente.

${ }^{1}$ BP - Biomassa de um perfilho; BF - Biomassa de folhas; BC - Biomassa de colmos; BPA - Biomassa da parte aérea; IAF - Índice de área foliar; RAF - Razão de área foliar; RMF - Razão de massa foliar.

Rev. Ceres, Viçosa, v. 64, n.2, p. 122-131, mar/abr, 2017 
houve aumento linear à medida que o início da inundação era retardado (Tabela 1 ).

Santos et al. (1999) também verificaram maior perfilhamento, com a inundação intermitente, na fase vegetativa, seguida de inundação contínua, nas fases reprodutiva e de maturação, em comparação com o perfilhamento obtido com a inundação contínua durante todo o ciclo do arroz. Avaliando formas de adubação nitrogenada em arroz irrigado, Larrosa et al. (2001) relataram que a aplicação de $\mathrm{N}$ em solo drenado, no início do perfilhamento, seguida de irrigação definitiva ou banho proporcionou maior número de perfilhos, por área, do que com a aplicação realizada em lâmina de água. Na aplicação precoce de $\mathrm{N}$, com posterior inundação, há incorporação do nutriente ao solo, aumenta a eficiência de seu uso e minimizam-se as perdas por volatilização. Essas perdas podem aumentar, caso o início da inundação seja retardado (Dunn \& Gaydon, 2011).

A biomassa de um perfilho, na floração, declinou linearmente, no primeiro ano, e apresentou resposta quadrática, no segundo, com as épocas de início da inundação, sendo 32 DAE a época estimada para a obtenção do valor máximo da biomassa de um perfilho (Tabela 1). Esses resultados corroboram os obtidos por Santos et al. (1999) que, com a inundação contínua durante todo o ciclo, obtiveram menor perfilhamento e maior biomassa de um perfilho determinada por ocasião do florescimento, em comparação com os mesmos parâmetros, obtidos com inundação intermitente, na fase vegetativa, seguida da inundação contínua, na fase reprodutiva. Com o atraso da época da fertilização nitrogenada em cobertura, houve redução linear da biomassa de um perfilho, BF, BC e BPA (Tabela 1). ABF apresentou resposta quadrática às épocas de início da inundação, no segun- do ano, sendo 35 DAE a época estimada para a obtenção da máxima biomassa de folha.

Aos efeitos das épocas da fertilização nitrogenada sobre o IAF e a RAF na floração, ajustaram-se os modelos quadráticos, sendo os valores máximos desses índices fisiológicos estimados por meio da equação de regressão, aos 32 DAE, no primeiro ano. Urchei et al. (2000) demostraram que o IAF de um genótipo varia com as condições ambientais, mas não com o número de dias até o seu valor máximo. Os efeitos das épocas de aplicação de N sobre o IAF, no segundo ano, foram lineares e negativos, assim como os das épocas de início da inundação, no primeiro ano. Menor área foliar resulta em menor produção biológica. A capacidade produtiva de uma comunidade vegetal é refletida pelo IAF, que é considerado por Jorge \& González (1997) como um índice importante em estudos de nutrição e crescimento vegetal. A RAF é um componente morfológico do crescimento; é a área foliar útil para a fotossíntese, ou seja, representa a superfície assimilatória por unidade de matéria seca total. Os valores de RAF, normalmente, decrescem com a ontogenia das plantas. No segundo ano, a RAF apresentou maiores valores no perfilhamento, a partir daí, declinou à medida que as plantas envelheciam, igualandose, no fim do período de florescimento, com o início do enchimento dos grãos, estádio R5 - R6, independentemente das épocas de início da inundação e da aplicação de $\mathrm{N}$ (Figura 4).

Maiores valores de RAF foram verificados com a inundação permanente iniciada mais tarde, $1,25 \mathrm{dm} \mathrm{g}^{-1}$ aos 60 DAE, e mais cedo, o fertilizante nitrogenado foi aplicado, $1,33 \mathrm{dm} \mathrm{g}^{-1}$ aos $15 \mathrm{DAE}$ (Figura 4). Essa época de aplicação de $\mathrm{N}$ propiciou RAF $31 \%$ maior que a época tardia, o que resultou em maior produtividade de grãos (Figura 3). Os

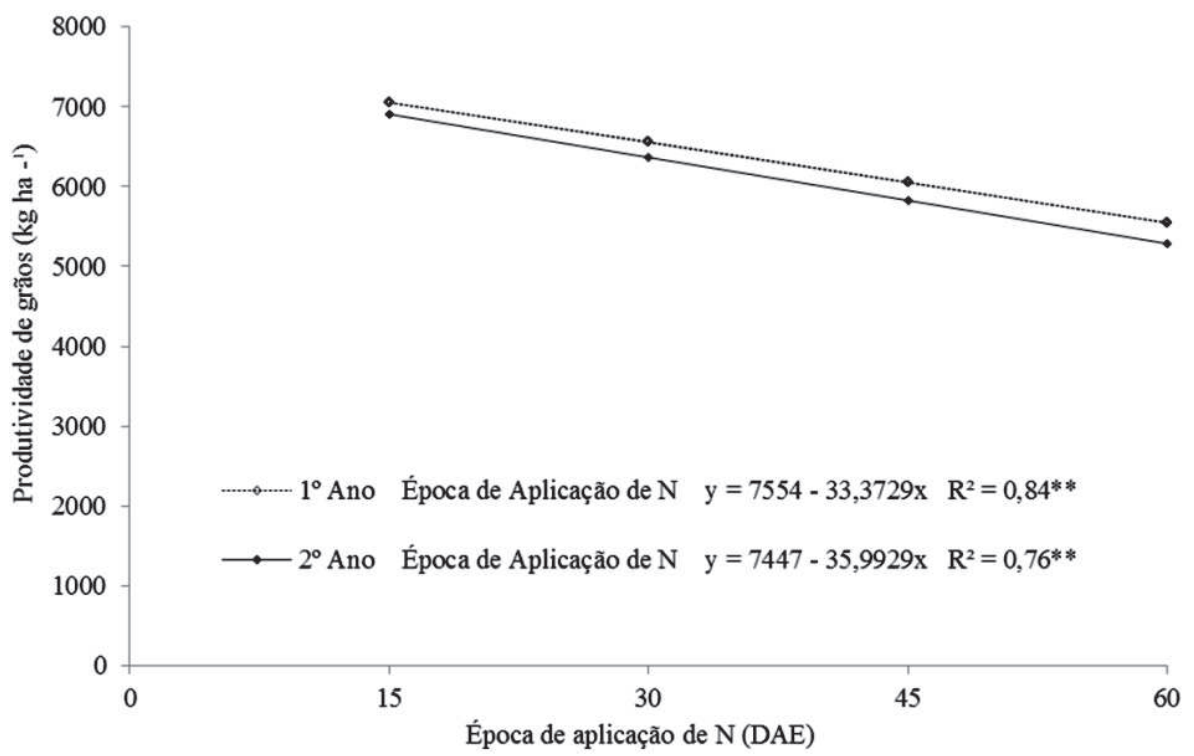

Figura 3: Produtividade de grãos do cultivar BRS Jaçanã de arroz irrigado, em razão de épocas de aplicação de N, nos dois anos. 
valores máximos de RAF no perfilhamento indicam que, nesse estádio de desenvolvimento, a maior parte do material fotossintetizado foi convertida em folhas, visando à maior captação da radiação solar disponível. O decréscimo da RAF até o final do ciclo do arroz pode ser explicado pelo surgimento de tecidos e estruturas que são drenos altamente competitivos, como flores e sementes, além do autossombreamento (Urchei et al., 2000), o que indica diminuição progressiva da quantidade de fotoassimilados destinada às folhas e aumento gradual de tecidos não assimilatórios. Muitas vezes, as condições de autossombreamento, que diminuem a eficiência fotossintética da cultura, diminuem também a transpiração, que, na maioria das vezes, é mais limitante para a produtividade de grãos.
Foi consistente o decréscimo da RAF, ao longo do desenvolvimento das plantas, com os resultados em arroz irrigado descritos por Costa et al. (2000). Urchei et al. (2000) atribuíram a redução da RAF à maior eficiência das folhas em converter energia luminosa e $\mathrm{CO}_{2}$ em matéria seca.

A RAF foi desmembrada em dois componentes: a área foliar específica (AFE) e a razão de massa foliar (RMF). A AFE é o componente morfológico e anatômico da RAF, pois relaciona a superfície com a biomassa da própria folha (Benincasa, 1988). A superfície é o componente morfológico e a massa é o componente anatômico, pois está relacionada com a composição interna, como número ou tamanho das células do mesófilo foliar. Independentemente das épocas de início da inundação e da aplicação de
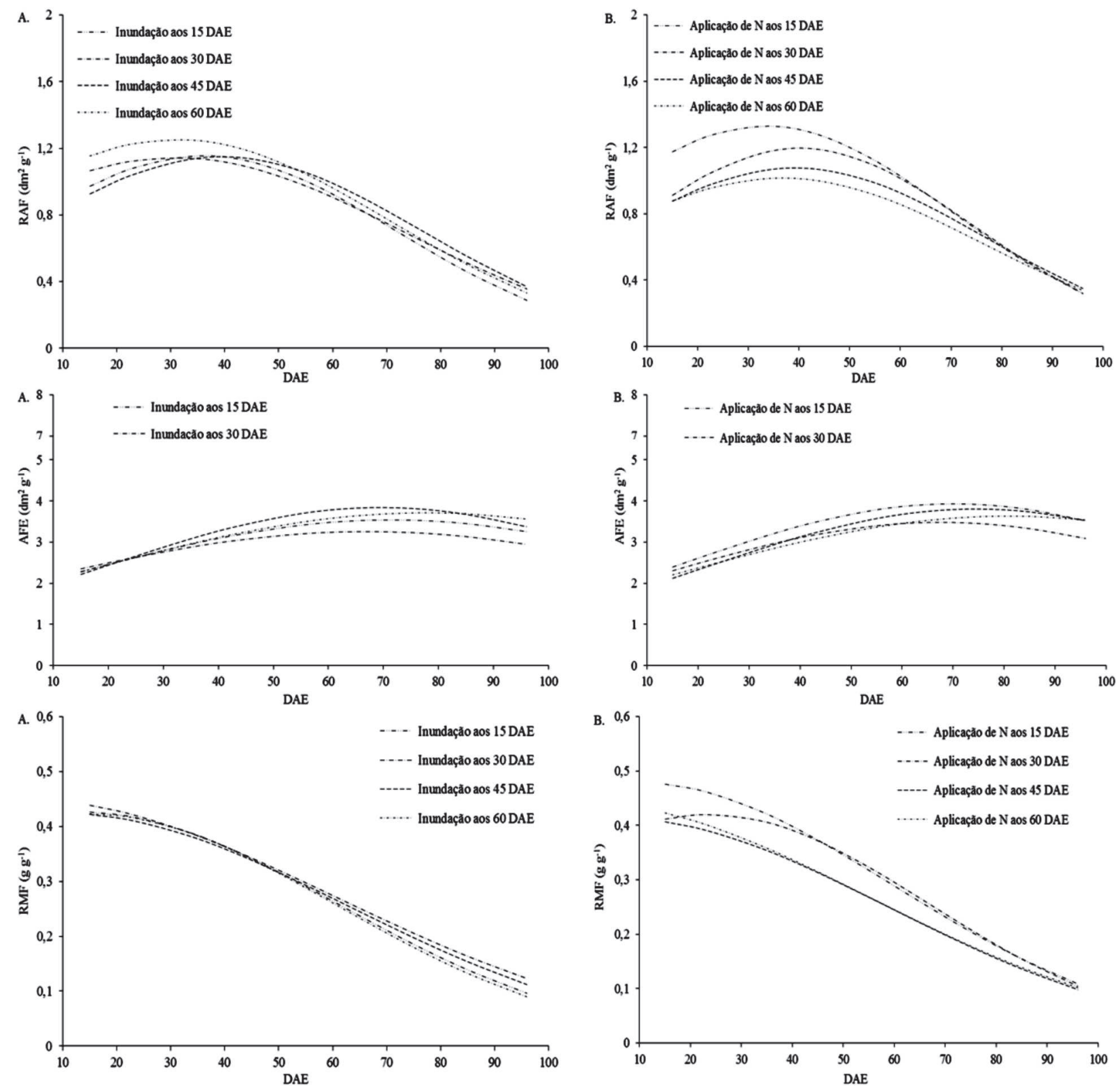

Figura 4: Evolução da razão da área foliar (RAF), da área foliar específica (AFE) e da razão de massa foliar (RMF) do cultivar BRS Jaçanã de arroz irrigado, em relação às épocas de início da inundação (A.) e de aplicação do N (B.) no segundo ano. 
$\mathrm{N}$, houve aumento da AFE com as mudanças ontogenéticas até próximo da floração, estádio R3 - R4, após o que a AFE declinou, à medida que as plantas envelheciam (Figura 4). Os maiores valores de AFE foram observados com a inundação iniciada tardiamente, $3,7 \mathrm{dm} \mathrm{g}^{-1}$, e com a aplicação de $\mathrm{N}$ mais cedo, 3,9 $\mathrm{dm} \mathrm{g}^{-1}$. Se for considerada a biomassa como expressão do volume foliar, o inverso da AFE indica a espessura da folha, ou seja, a relação BF/Área Foliar, que é chamada massa específica foliar (MEF).

A RMF é um componente basicamente fisiológico, razão entre a biomassa retida nas folhas e a acumulada na planta toda. Houve redução da RMF com as mudanças ontogenéticas até o final do ciclo do arroz, independentemente das épocas de início da inundação e da aplicação de N (Figura 4). As épocas de início da inundação não afetaram a RMF, mas a aplicação mais cedo de $\mathrm{N}$ propiciou maior valor, $0,48 \mathrm{~g} \mathrm{~g}^{-1}$, mostrando que há maior alocação de assimilados para as folhas em desenvolvimento, sendo, na ocasião, o dreno metabólico preferencial. O decréscimo dos valores de RMF ao longo do ciclo da cultura foi devido, provavelmente, à menor fração de material retido na folha, ou seja, à maior exportação para as demais partes da planta, à medida que a fertilização nitrogenada foi retardada. A RMF, determinada por ocasião do florescimento, reduziu-se linearmente, com o atraso das épocas de aplicação de $\mathrm{N}$, no primeiro ano, e apresentou resposta quadrática, no segundo, às épocas de início da inundação (Tabela 1), sendo 32 DAE a época estimada para a obtenção do seu valor máximo. Avaliando os efeitos de manejo de água sobre índices fisiológicos do arroz irrigado, em várzea tropical, Santos et al. (1999) obtiveram biomassa retida nas folhas maior que a acumulada na planta toda com a inundação intermitente na fase vegetativa, seguida de inundação contínua nas fases reprodutiva e de maturação, em comparação com a obtida com inundação contínua durante todo o ciclo da cultura. Considerando-se que as folhas são os centros de produção de biomassa, mediante a fotossíntese, e que o resto da planta depende de exportação de material da folha, a RMF expressa a fração de biomassa não exportada das folhas para o resto da planta. A maior ou menor exportação de material da folha se deve à sua constituição genética, a qual é influenciada pelo ambiente. A eficiência em exportação pode ser muito importante para a produção de grãos, principalmente quando se comparam produtividades entre genótipos.

A DAF declinou linearmente com as épocas de início da inundação, no primeiro ano, com redução de $1,71 \mathrm{~m}^{2} \mathrm{~m}^{-}$ ${ }^{2}$ para cada dia de atraso na inundação (Figura 5). No segundo ano, aos efeitos das épocas de início da inundação sobre a DAF ajustou-se o modelo quadrático, sendo 37 DAE a época estimada por meio da equação de regressão para a obtenção do valor máximo da DAF, 411,53 $\mathrm{m}^{2}$ dia $\mathrm{m}^{-2}$. Dunn e Gaydon (2011) mencionam que o atraso da inundação contínua aumenta o período de crescimento da cultura. Quanto às épocas de aplicação de $\mathrm{N}$, os efeitos sobre a DAF foram lineares e negativos, com maior redução no segundo ano, o que correspondeu a $4,22 \mathrm{~m}^{2} \mathrm{~m}^{-2}$ para cada dia de atraso na fertilização nitrogenada. A relação entre a DAF e a produtividade de grãos foi linear e positiva (Figura 6), o que indica que cada unidade de aumento da DAF corresponde a um aumento de 9 e $7 \mathrm{~kg} \mathrm{ha}^{-1}$ de grãos de arroz, no primeiro e segundo anos, respectivamente. A DAF é indicadora da persistência da superfície assimilatória durante o período de crescimento da cultura. O potencial produtivo de um cultivar é relacionado com a DAF. A maior área foliar e sua duração estão relacionadas com a maior

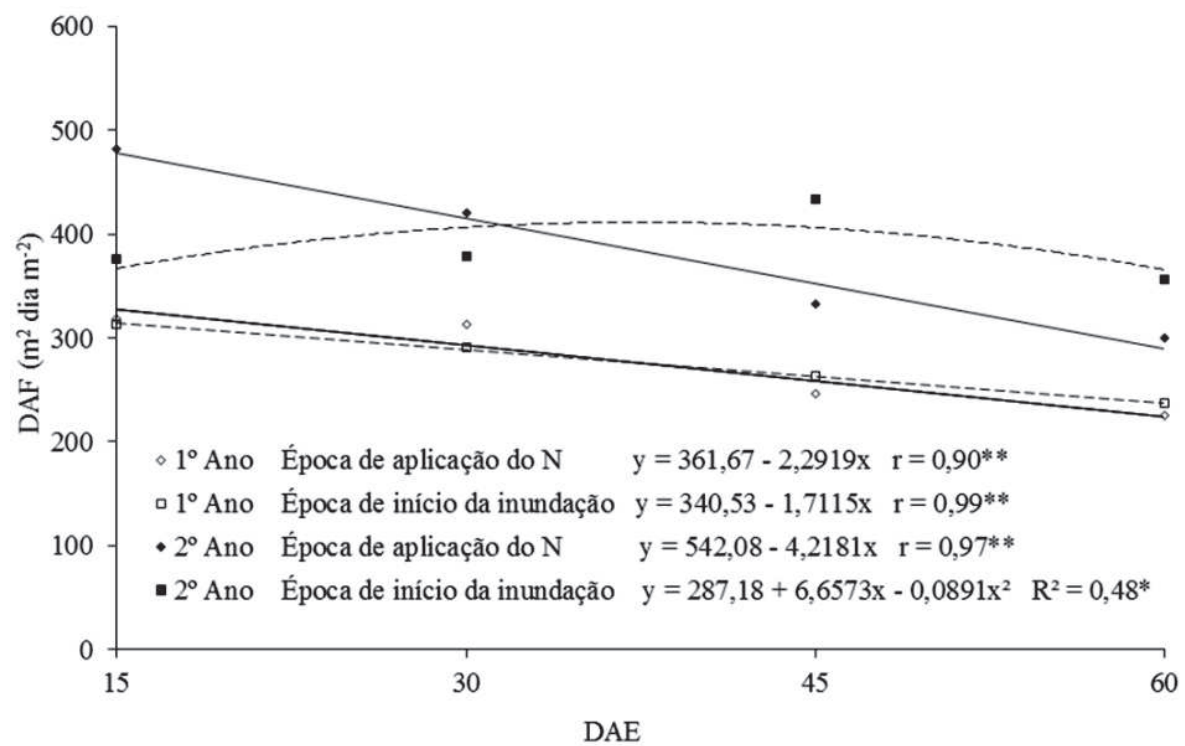

Figura 5: Relação entre a duração da área foliar (DAF) e as épocas de início da inundação e de aplicação de N do cultivar BRS Jaçanã de arroz irrigado, nos dois anos. 
produtividade de grãos de arroz, o que permite o fornecimento de elevada quantidade de fotoassimilados por um período maior (Santos \& Costa, 1997; Costa et al., 2000; Falqueto et al., 2009). A produtividade das culturas é correlacionada positivamente com os índices fisiológicos. Essa relação pode ser explicada pela proporção da radiação interceptada, isto é, folhas maiores e que permanecem verdes por mais tempo interceptam mais radiação e, frequentemente, a quantidade de radiação interceptada apresenta relação linear com a biomassa. Quanto mais rápido a cultura atingir o IAF máximo, e quanto mais tempo a área foliar permanecer ativa, maior será a produtividade de grãos. Em condições tropicais, Costa et al. (2000) verificaram que a produtividade de grãos do arroz irrigado foi correlacionada com os índices fisiológicos, apresentando os mais altos coeficientes de determinação com o crescimento radicular e a DAF. No sistema de cultivo de terras altas, as correlações entre a DAF e a produtividade de grãos do cultivar Guarani foram positivas, independentemente do emprego de irrigação suplementar (Santos \& Costa, 1997).

A EAF aumentou linearmente com o atraso das épocas de início da inundação e de aplicação de N (Figura 7). A EAF passou de 1,77 para 2,20 e de 1,78 para 2,05 g dia de grãos de arroz por $\mathrm{m}^{-2}$ de folha, com o atraso da inundação e da adubação, respectivamente. Esses aumentos foram equivalentes, pois corresponderam a $0,007 \mathrm{~g}$ de grãos de

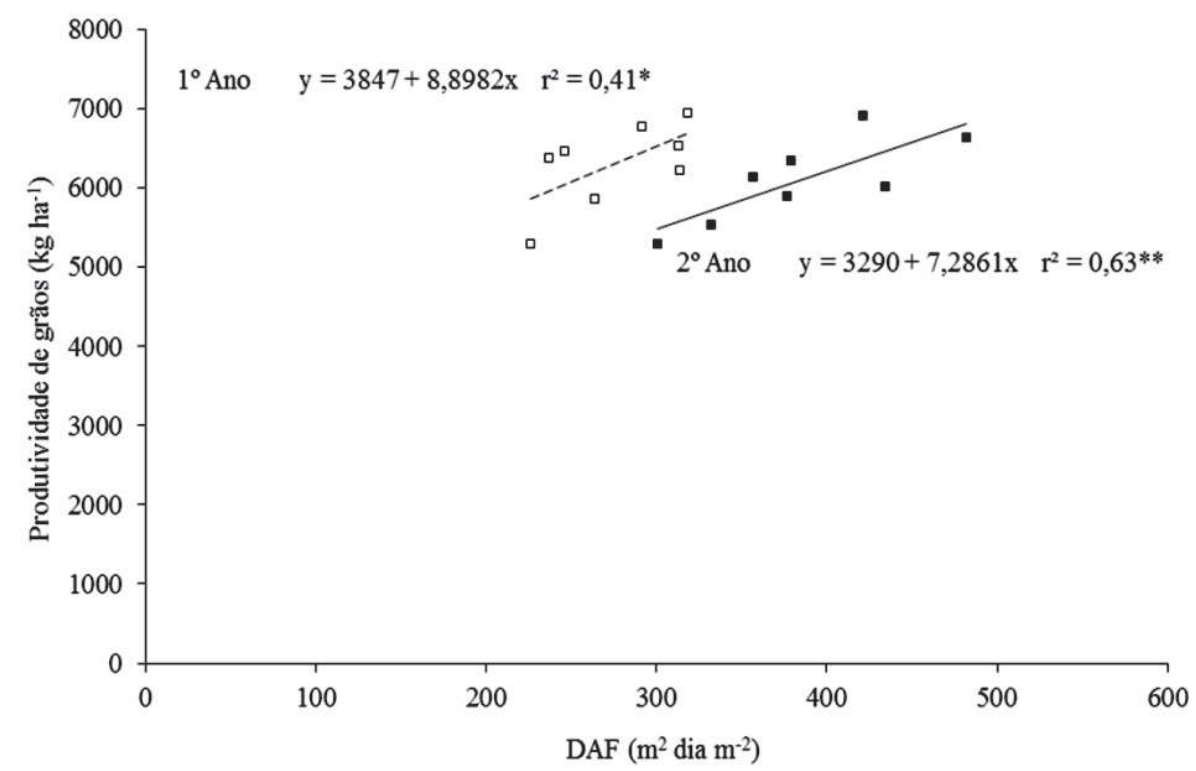

Figura 6: Relação entre a duração da área foliar (DAF) e a produtividade de grãos do cultivar BRS Jaçanã de arroz irrigado, nos dois anos.

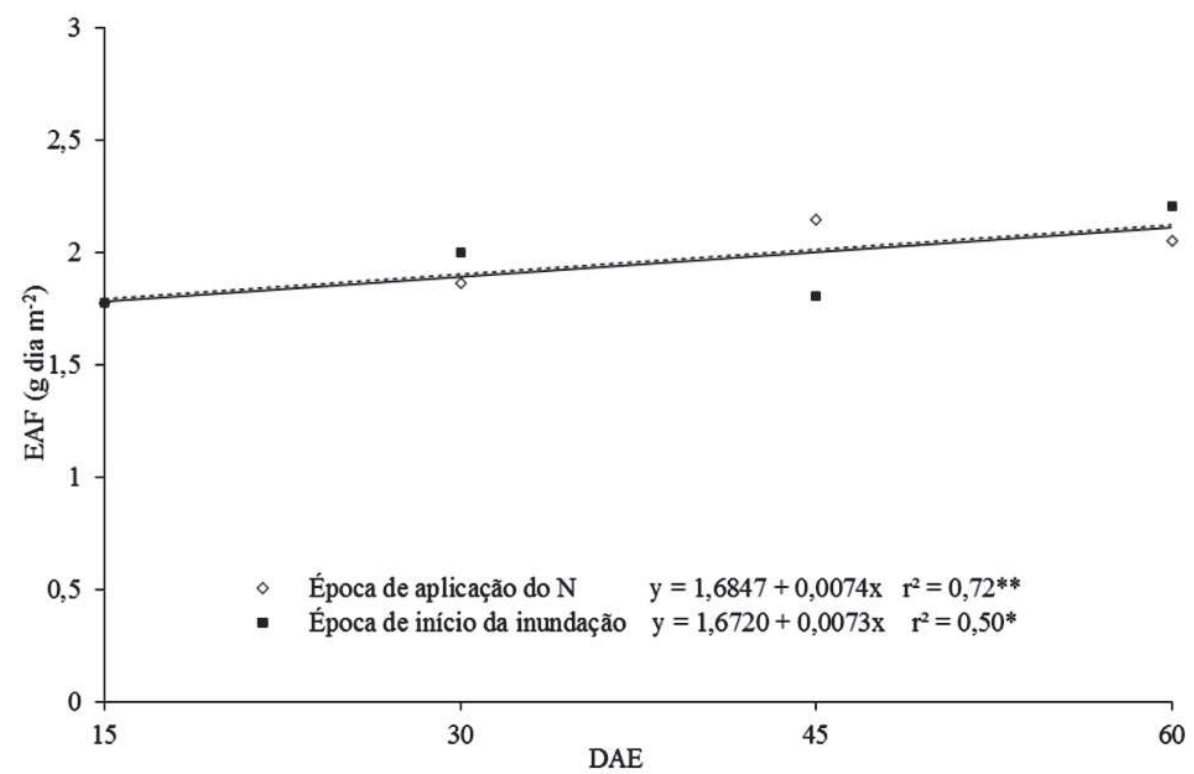

Figura 7: Relação entre a eficiência de área foliar (EAF) e as épocas de início da inundação e de aplicação de N, do cultivar BRS Jaçanã de arroz irrigado (média dos dois anos).

Rev. Ceres, Viçosa, v. 64, n.2, p. 122-131, mar/abr, 2017 
arroz por metro quadrado de folha para cada dia de atraso do início da inundação permanente e da adubação nitrogenada. É provável que as respostas da EAF se devam ao fato de os efeitos dos atrasos das épocas de início da inundação e de aplicação de $\mathrm{N}$ terem sido proporcionalmente mais expressivos para a DAF que para a produtividade de grãos. Isso evidencia que a planta de arroz apresenta maior área foliar que o necessário para atingir seu potencial produtivo. Nesse caso, há consumo de luxo; a fonte é maior que o dreno. Com isso, maior área foliar pode não resultar, proporcionalmente, em mais grãos.

\section{CONCLUSÕES}

Área foliar maior que permanece verde por mais tempo proporciona maior produtividade de grãos. Atraso do início da inundação aumenta o perfilhamento, a razão de área foliar e a área foliar específica e decresce a biomassa da parte aérea, o índice de área foliar e a duração de área foliar.

Os índices fisiológicos reduzem-se à medida que se atrasa a fertilização nitrogenada em cobertura.

O emprego da inundação e da adubação nitrogenada no arroz irrigado tardiamente reduz proporcionalmente mais a área foliar que a produtividade de grãos, o que resulta em maior eficiência de área foliar.

A adubação nitrogenada em cobertura, efetuada por ocasião do início do perfilhamento, e a inundação contínua no período médio de perfilhamento resultam em aumento dos índices fisiológicos relacionados positivamente com a produtividade de grãos do arroz irrigado.

\section{AGRADECIMENTOS}

Os autores agradecem ao Conselho Nacional de Desenvolvimento Científico e Tecnológico (CNPq), pelo suporte financeiro e pelas bolsas de Produtividade em Pesquisa concedidas.

\section{REFERÊNCIAS}

Benincasa MMP (1988) Análise de crescimento de plantas: noções básicas. Jaboticabal, FUNEP. 41p.

Bosco LC, Grimm EL \& Streck NA (2009) Crescimento e desenvolvimento de genótipos de arroz cultivados em solo alagado e não-alagado. Revista Ceres, 56:796-804.

Carlesso R, Hernandez MGR, Righes AA \& Jadoski SO (1998) Índice de área foliar e altura de plantas de arroz submetidas a diferentes práticas de manejo. Revista Brasileira de Engenharia Agrícola e Ambiental, 2:268-272.

Chacín Lugo F (1997) Cursos avances recientes en el diseño y analisis de experimentos. Caracas, Universidad Central de Venezuela. $145 \mathrm{p}$.

Costa EG de C, Santos AB dos \& Zimmermann FJP (2000) Crescimento da cultura principal e da soca de genótipos de arroz irrigado por inundação. Pesquisa Agropecuária Brasileira, 35:1949-1958.
Counce PA, Keisling TC \& Mitchell AJA (2000) Uniform, objective, and adaptative system for expressing rice development. Crop Science, 40:436-443.

Dunn BW \& Gaydon DS (2011) Rice growth, yield and water productivity responses to irrigation scheduling prior to the delayed application of continuous flooding in south-east Australia. Agricultural Water Management, 98:1799-1807.

Fageria NK \& Baligar VC (2005) Enhancing nitrogen use efficiency in crop plants. Advances in Agronomy, 88:97-185.

Fageria NK, Santos AB dos \& Coelho AM (2011) Growth, yield and yield components of lowland rice as influenced by ammonium sulfate and urea fertilization. Journal of Plant Nutrition, 34:371-386.

Fageria NK, Santos AB dos \& Cutrim V dos A (2008) Dry matter and yield of lowland rice genotypes as influence by nitrogen fertilization. Journal of Plant Nutrition, 31:788-795.

Fageria NK, Santos AB dos \& Cutrim V dos A (2009) Nitrogen uptake and its association with grain yield in lowland rice genotypes. Journal of Plant Nutrition, 2:1965-1974.

Fallah A (2011) Interactive effects of nitrogen and irrigation methods on the growth and yield of rice in Amol area. International Journal of Agriculture and Crop Sciences, 3:111113.

Falqueto AR, Cassol D, Magalhães Júnior AM de, Oliveira AC de \& Bacarin MA (2009) Crescimento e partição de assimilados em cultivares de arroz diferindo no potencial de produtividade de grãos. Bragantia, 68:563-571.

Jorge Y \& Gonzalez F (1997) Estimación del área foliar em los cultivos de ají y tomate. Agrotecnia de Cuba, 27:123-126.

Larrosa RFM, Marchezan E, Aita C \& Coradini JZ (2001) Eficiência da aplicação de nitrogênio no perfilhamento do arroz em três manejos de irrigação. Ciência Rural, 31:745-749.

Marchesan E, Grohs M, Walter M, Silva LS da \& Formentini TC (2013) Agronomic performance of rice to the use of urease inhibitor in two cropping systems. Revista Ciência Agronômica, 44:594-603

Pereira AR \& Machado EC (1987) Análise quantitativa do crescimento de comunidades vegetais. Campinas, IAC. 33p. (Boletim Técnico, 114).

Qi X, Nie L, Liu H, Peng S, Shah F, Huang J, Cui K \& Sun L (2012) Grain yield and apparent $\mathrm{N}$ recovery efficiency of dry directseeded rice under different $\mathrm{N}$ treatments aimed soil ammonia volatilization. Field Crops Research, 134:138-143.

Santos AB dos \& Costa JD (1997) Crescimento de arroz de sequeiro em diferentes populações e irrigação suplementar. Pesquisa Agropecuária Brasileira, 32:591-599.

Santos AB dos, Fageria NK, Stone LF \& Santos C (1999) Manejo de água e de fertilizante potássico na cultura de arroz irrigado. Pesquisa Agropecuária Brasileira, 34:565-573.

Scivittaro WB, Gonçalves DRN, Vale MLC \& Ricordi VG (2010) Perdas de nitrogênio por volatilização de amônia e resposta do arroz irrigado à aplicação de ureia tratada com o inibidor de uréase NBPT. Ciência Rural, 40:1283-1289.

Urchei MA, Rodrigues JD \& Stone LF (2000) Análise de crescimento de duas cultivares de feijoeiro sob plantio direto e preparo convencional. Pesquisa Agropecuária Brasileira, 35:497-506. 